\title{
Metabolic syndrome components and acute pancreatitis: a case-control study in China
}

\author{
Zhemin Shen ${ }^{1 \dagger}$, Xueqiao Wang ${ }^{2 \dagger}$, Zili Zhen $^{1}$, Yao Wang ${ }^{3}$ and Peilong Sun ${ }^{1 *}$
}

\begin{abstract}
Background: Acute pancreatitis (AP) is a common inflammatory disorder of the pancreas. Recent evidence has shown that metabolic syndrome is positively correlated with the severity of AP. However, only a few studies have revealed the relationship between metabolic syndrome and the occurrence of AP. We therefore elucidated the association between metabolic syndrome and the occurrence of AP.

Methods: A hospital-based case-control study was conducted. A total of 705 patients admitted to our hospital from January 2016 to December 2018 were included in the study. Subjects were divided into case and control groups according to their diagnosis: (1) According to the revised Atlanta classification from 2012, patients diagnosed with AP were enrolled in the case group. (2) Patients without a history of AP or any disease related to metabolic syndrome were allocated into the control group. Controls were matched to cases individually by sex and age (control/case ratio $=1$ ).

Results: The incidence rate of metabolic syndrome in AP patients was 30.9\%, which was more frequent than that in controls (13.2\%) (OR 2.837; 95\% Cl 1.873-4.298, $p<0.001)$. In the multivariate regression analysis, a history of smoking or alcohol consumption and biliary stones were significantly associated with AP (OR 2.441; 95\% Cl 1.865-5.172, $p<0.001$; OR 1.777; 95\% Cl 1.060-2.977, $p=0.029 ;$ OR 28.995; 95\% Cl 13.253-63.435, $p<0.001$ ). In addition, the occurrence of AP was significantly associated with total cholesterol (TC) (OR 1.992; 95\% Cl 1.246-3.183, $p=0.004)$, triglyceride (TG) (OR 2.134; 95\% Cl 1.403-3.245, $p<0.001$ ), hyperglycaemia (OR 2.261; 95\% Cl 1.367-3.742, $p=0.001)$, and apolipoprotein A (Apo A) (OR 0.270; 95\% Cl 0.163-0.447, $p<0.001$ ).
\end{abstract}

Conclusions: Metabolic syndrome and its components were associated with AP occurrence.

Keywords: Acute pancreatitis, Metabolic syndrome, Hyperglycaemia, Hyperlipidaemia, Obesity, Hypertension

\section{Background}

Acute pancreatitis (AP) is a pancreatic inflammatory disorder that may cause life-threatening consequences due to severe inflammatory responses [1]. According to a survey, the annual incidence rate of AP has increased by $100 \%$ over the past several decades [2]. This has posed a great threat to human health and become one of the

\footnotetext{
*Correspondence: sunpeilong@fudan.edu.cn

${ }^{\dagger}$ Zhemin Shen and Xueqiao Wang contributed equally to this work

1 Department of General Surgery, Jinshan Hospital, Fudan University,

Shanghai, China

Full list of author information is available at the end of the article
}

largest contributors to aggregate medical costs [3]. The main pathogenic causes of AP are biliary stones and alcohol consumption. Other factors, such as smoking and genetic factors, are also considered to be related to the occurrence of AP [3]. However, the pathogenic immune mechanism of AP remains elusive, and the potential factors related to the stimulus of inflammation are still under investigation.

Due to the huge economic development and social progresses made in China over past decades, the lifestyles and daily diets of Chinese people have changed substantially. In turn, this has led to the high prevalence of metabolic syndrome in China $(27.9 \%$ in men 
and $26.8 \%$ in women) and has caused serious public health problems [4]. Metabolic syndrome is defined as four interconnected factors: hyperglycaemia, hyperlipidaemia (particularly increased triglycerides [TGs] and low high-density lipoprotein [HDL] cholesterol), obesity and hypertension. It is generally considered a risk factor for cardiovascular diseases [5]. Although there is still no universally accepted mechanism of metabolic syndrome [6], the best evidence suggests that the four components of metabolic syndrome may be intercorrelated with each other by sharing common pathophysiological processes. These processes mainly consist of insulin resistance, visceral adiposity, atherogenic dyslipidaemia and endothelial dysfunction [7]. In addition, given that the four components are more likely to appear together more than might be expected by chance, metabolic syndrome should thus be considered an overall concept. It can gradually lead patients to a proinflammatory state that is associated with a series of diseases, such as venous thrombosis and psoriasis [7-9]. Since it is well believed that there is an interrelation between metabolic syndrome and inflammation [10, 11], we suspect that metabolic syndrome may also have a significant impact on AP. Although some studies have demonstrated that metabolic syndrome is positively associated with the severity of AP $[1,12]$, there is still a lack of data showing the relationship between metabolic syndrome and the occurrence of AP in the Chinese population, and most of them involved mainly the single component of metabolic syndrome, such as obesity or hyperglycaemia, rather than as an overall concept $[1,13-16,20]$. Moreover, these studies were mainly conducted on western countries, which may differ from those in eastern populations. To address these issues, we examined relevant data to investigate (1) the association between metabolic syndrome and the occurrence of AP, (2) the association between each metabolic syndrome component and the occurrence of AP, (3) the association between the number of metabolic syndrome components and the occurrence of AP.

\section{Methods}

\section{Ethical approval}

The study was conducted according to the Declaration of Helsinki and approved by the institutional research board of Jinshan Hospital (IEC-2020-S21). Informed consent was waived.

\section{Study population}

A hospital-based case-control study was conducted. A total of 705 patients (349 AP patients and 356 controls) admitted to our hospital from January 2016 to December 2018 were included in the study. According to the revised Atlanta classification from 2012 [17], AP was defined if at least two of the following three criteria were presented: acute attack of severe upper abdominal pain with or without radiating to the back; serum amylase or lipase elevation at least three times above the upper limit of normal level; and typical acute pancreatitis imaging found on computed tomography (CT) scan. Only patients with a first attack of AP were included, while patients with relapse of AP or chronic pancreatitis were excluded. The controls were selected from patients admitted to department of anorectal surgery, department of otorhinolaryngology head and neck surgery and department of orthopedics. Their diagnosis mainly consisted of haemorrhoids, sudden sensorineural hearing loss, tonsil hypertrophy, epiglottic cyst and disc herniation. The controls were frequency matched to cases by sex and exact age. Control subjects were excluded if they had AP history. Participants who had histories of any cardiovascular disease (except hypertension) or psoriasis were not enrolled in the two groups. Last, subjects were excluded if they were younger than 18 years, pregnant, underwent surgery within 1 month or had a cancer history.

All patients admitted were given standard medical treatment. In AP group, patients received treatment including fasting, early fluid resuscitation, analgesia, and nutritional support. In non-AP group, patients mainly received pre-operation examinations such as ECG (Electrocardiogram) and chest X-Ray after admission since most of the patients were about to undergo surgery in the next few days.

\section{Clinical data collection}

Data were collected by researchers who were not informed of the detailed information of the study until collection was completed. The collected data were from computer-based case reports and were checked by another two researchers to ensure that there were no inconsistencies or errors. The following data of patients were collected: sex; age; smoking history; alcohol drinking history ( $>14$ drinks/week in women or $>21$ drinks/ week in men); biliary stones history; history of hepatitis $\mathrm{B}$ or hepatitis $\mathrm{C}$; body mass index (BMI); blood pressure; and laboratory tests, including total cholesterol (TC), TG, HDL, low-density lipoprotein (LDL), apolipoprotein A (Apo A), apolipoprotein B (Apo B), and fasting plasma glucose (FPG). BMI was calculated as body weight $(\mathrm{kg})$ divided by square of the height $(\mathrm{m})$. Blood pressure was measured by a mercury sphygmomanometer when patients were in a supine position and after $20 \mathrm{~min}$ of rest. Blood samples were collected from the median cubital vein of each patient after $8 \mathrm{~h}$ of fasting. Fasting venous blood was collected in polystyrene tubes and rapidly 
transmitted to the laboratory to ensure the accuracy of our indexes.

\section{Metabolic syndrome components}

The diagnostic criteria for metabolic syndrome were defined according to National Cholesterol Education Program Adult Treatment Panel III (NCEP/ATP-III) [18] and modified by the Asia-Pacific criteria [19]. The criteria include (1) hypertension (blood pressure $\geq 130 / 85 \mathrm{mmHg}$ or ongoing anti-hypertensive treatment), (2) hyperlipidaemia ( $\mathrm{TG} \geq 150 \mathrm{mg} / \mathrm{dL}$ or $\mathrm{HDL} \leq 40 \mathrm{mg} / \mathrm{dL}$ in men and $50 \mathrm{mg} / \mathrm{dL}$ in women or ongoing anti-lipidaemic treatment), (3) hyperglycaemia (FPG $\geq 110 \mathrm{mg} / \mathrm{dL}$, previously physician-diagnosed type 2 diabetes mellitus [T2DM] or ongoing antidiabetic treatment) and (4) obesity (BMI $\geq 25 \mathrm{~kg} / \mathrm{m}^{2}$ or waist circumference $\geq 90 \mathrm{~cm}$ for men and $80 \mathrm{~cm}$ for women).

\section{Statistical analysis}

Quantitative data were expressed with mean \pm standard deviation (SD) or median with $25^{\text {th }}$ and $75^{\text {th }}$ percentiles as appropriate. For normal distributed quantitative data, independent sample t-test was used to compare the differences between the two groups. For non-parametric quantitative data, Mann-Whitney test was used to detect the statistical significance. Qualitative data were expressed in number ( $\mathrm{n}$ ) and percentage (\%). Fisher's exact test or chi-square test was used to compare the differences. Univariate logistic regression analysis was used to preliminarily assess whether these individual variables were predictive factors of AP occurrence. Odds ratios (ORs) and corresponding 95\% confidence intervals (CIs) were calculated. Univariate and multivariate logistic regression were used to further test the OR value. The accuracy of each marker in predicting the occurrence of $\mathrm{AP}$ was assessed by using receiver operating characteristic (ROC) curves. A $P$ value $<0.05$ was defined as statistically significant. IBM SPSS v22 (SPSS, Chicago, Illinois, USA) and MedCalc statistical software packages, version 10 (MedCalc, Mariakerke, Belgium), were used for statistical analysis.

\section{Results}

Characteristics of study subjects

Based on the inclusion and exclusion criteria, 705 subjects, including 349 AP patients and 356 non-AP patients, were enrolled in our study. Table 1 shows the characteristics of the subjects. No significant differences between AP patients and non-AP patients were found with respect to age $(p=0.989)$, gender $(p=0.923)$, hepatitis C $(p=0.349)$ and Apo B $(p=0.198)$. However, we noted that AP patients were significantly associated

Table 1 Basic characteristics

\begin{tabular}{|c|c|c|c|}
\hline & Non-AP patients $(n=356)$ & AP patients $(n=349)$ & $p$ \\
\hline Mean age, years (SD) & $51.2 \pm 15.9$ & $51.2 \pm 15.9$ & 0.989 \\
\hline \multicolumn{4}{|l|}{ Gender, n (\%) } \\
\hline Female & $140(39.3)$ & $136(39.0)$ & \\
\hline Male & $216(60.7)$ & $213(61.0)$ & 0.923 \\
\hline Smoking history, n (\%) & $62(17.4)$ & $125(35.8)$ & $<0.001$ \\
\hline Alcohol drinking history, n (\%) & $53(14.9)$ & $101(28.9)$ & $<0.001$ \\
\hline Biliary stones, n (\%) & $8(2.3)$ & $101(28.9)$ & $<0.001$ \\
\hline Hepatitis B, n (\%) & $17(4.8)$ & $7(2.0)$ & 0.049 \\
\hline Hepatitis C, n (\%) & $3(0.8)$ & $1(0.3)$ & 0.349 \\
\hline $\mathrm{BMI}, \mathrm{kg} / \mathrm{m}^{2}$ (IQR) & $23.8 \pm 3.5$ & $24.8 \pm 3.7$ & $<0.001$ \\
\hline $\mathrm{TC}, \mathrm{mg} / \mathrm{dL}(\mathrm{IQR})$ & $178.0(153.7,209.3)$ & $180.3(145.6,235.1)$ & $<0.001$ \\
\hline $\mathrm{TG}, \mathrm{mg} / \mathrm{dL}(\mathrm{IQR})$ & $101.8(77.0,157.5)$ & $131.9(81.4,349.6)$ & $<0.001$ \\
\hline $\mathrm{HDL}, \mathrm{mg} / \mathrm{dL}(\mathrm{IQR})$ & $99.1(86.7,117.7)$ & $90.3(74.3,112.4)$ & $<0.001$ \\
\hline $\mathrm{LDL}, \mathrm{mg} / \mathrm{dL}$ (IQR) & $269.9(224.8,318.6)$ & $258.4(198.2,236.3)$ & 0.030 \\
\hline Apo A, g/L (IQR) & $1.2(1.1,1.4)$ & $1.1(0.9,1.3)$ & $<0.001$ \\
\hline Apo B, g/L (IQR) & $0.9(0.7,1.0)$ & $0.8(0.7,1.0)$ & 0.198 \\
\hline $\mathrm{FPG}, \mathrm{mg} / \mathrm{dL}(\mathrm{IQR})$ & $97.8(89.4,112.1)$ & $132.8(107.4,172.7)$ & $<0.001$ \\
\hline Anti-diabetic therapy, n (\%) & $27(79.4)$ & $59(64.8)$ & 0.118 \\
\hline
\end{tabular}

Data were numbers and percentages, or median (25th, 75th percentile), as appropriate

n number, IQR interquartile range, $B M I$ body mass index (calculated as weight in kilograms divided by height in meters squared), $T C$ total cholesterol, $T G$ triglyceride, $H D L$ high density lipoprotein, $L D L$ low density lipoprotein, $A p o A$ apolipoprotein $A, A p o B$ apolipoprotein $B, F P G$ fasting plasma glucose

SI conversion factors: TC: $1 \mathrm{mg} / \mathrm{dL}=0.0259 \mathrm{mmol} / \mathrm{L} ; \mathrm{HDL}, \mathrm{LDL}, \mathrm{TG}: 1 \mathrm{mg} / \mathrm{dL}=0.0113 \mathrm{mmol} / \mathrm{L} ; \mathrm{FPG}: 1 \mathrm{mg} / \mathrm{dL}=0.0555 \mathrm{mmol} / \mathrm{L}$ 
with cigarette smoking $(p<0.001)$, alcohol consumption $(p<0.001)$, biliary stones history $(p<0.001)$, hepatitis B $(p=0.049)$, and BMI $(p<0.001)$ and TC $(p<0.001)$, TG $(p<0.001)$, HDL $(p<0.001)$, LDL $(p=0.030)$, Apo A $(p<0.001)$, and FPG $(p<0.001)$ than controls. In patients with diabetes mellitus, 27 patients (79.4\%) received anti-diabetic therapy in control group, while 59 patients $(64.8 \%)$ received treatment in case group. There were no significant differences $(p=0.118)$ between the two groups regarding the anti-diabetic therapy.

\section{Effect of metabolic syndrome components on AP}

In univariate analysis, both of increased values of TG and decreased values of HDL were associated with the occurrence of AP (OR 2.313; 95\% CI 1.690-3.167, $p<0.001$; OR 0.582; 95\% CI 0.431-0.786, $\mathrm{p}<0.001$ ) (shown in Table 2). Additionally, significant differences were observed between the two groups in patients with obesity, hyperglycaemia and hypertension(OR 1.608; 95\% CI 1.1862.181, $p=0.002$; OR 3.209; 95\% CI 2.112-4.876, $\mathrm{p}<0.001$; OR 1.473; 95\% CI 1.089-1.991, $\mathrm{p}=0.012$ ). In multivariate logistic regression models, after adjustment for smoking and alcohol drinking history, biliary stones history, Apo A and the components of metabolic syndrome, the results revealed that AP was associated with smoking history; alcohol consumption history; biliary stones history; elevated levels of TC, TG; hyperglycaemia and lower values of Apo A (OR 2.441; 95\% CI 1.865-5.172, $p<0.001$; OR 1.777; 95\% CI 1.060-2.977, $p=0.029$; OR 28.995; 95\% CI 13.253-63.435, $p<0.001$; OR 1.992; 95\% CI 1.246-3.183, $p=0.004$; OR 2.134; 95\% CI 1.403-3.245, $p<0.001$; OR 2.261 ; $95 \%$ CI $1.367-3.742, p=0.001$ and OR 0.270 ; $95 \%$ CI $0.163-0.447, p<0.001$, respectively). However, obesity was not observed to be associated with the occurrence of AP $(p=0.246)$ (shown in Table 3). After adjusting for smoking and alcohol drinking history, biliary stones, the prevalence of metabolic syndrome was more common in AP patients (30.9\%) than in those without AP (13.2\%) (OR 2.837; 95\% CI 1.873-4.298, $p<0.001$ ) (shown in Table 4). As shown in Table 5 and Fig. 1, for all AP patients, increased values of TG and low Apo A and FPG predicted AP with statistical significance $(p<0.001$,

Table 2 Univariate analysis examining the components of the metabolic syndrome

\begin{tabular}{lcccc}
\hline & Non-AP patients $(\mathbf{n}=\mathbf{3 5 6})$ & AP patients $(\mathbf{n}=\mathbf{3 4 9})$ & OR $(\mathbf{9 5 \%} \mathrm{Cl})$ & $\boldsymbol{p}$ \\
\hline $\mathrm{TG} \geq 150 \mathrm{mg} / \mathrm{dL}, \mathrm{n}(\%)$ & $97(27.2)$ & $162(46.4)$ & $2.313(1.690-3.167)$ & \\
$\mathrm{HDL} \geq 40 \mathrm{mg} / \mathrm{dL}(\mathrm{M})$ or $\geq 50 \mathrm{mg} / \mathrm{dL}$ & $183(51.4)$ & $133(38.1)$ & $0.582(0.431-0.786)$ & \\
$(\mathrm{F}), \mathrm{n}(\%)$ & & & & $<0.001$ \\
Obesity, $\mathrm{n}(\%)$ & $120(33.7)$ & $157(45.0)$ & $1.608(1.186-2.181)$ & 0.001 \\
Hyperglycaemia, $\mathrm{n}(\%)$ & $37(10.4)$ & $93(26.7)$ & $3.209(2.112-4.876)$ & $<0.001$ \\
Hypertension, $\mathrm{n}(\%)$ & $129(36.2)$ & $159(45.6)$ & $1.473(1.089-1.991)$ & 0.012 \\
\hline
\end{tabular}

$O R$ odds ratio, $T G$ triglyceride, $H D L$ high density lipoprotein

SI conversion factors: $\mathrm{HDL}, \mathrm{TG}: 1 \mathrm{mg} / \mathrm{dL}=0.0113 \mathrm{mmol} / \mathrm{L}$

Table 3 Multivariate analysis examining the components of the metabolic syndrome

\begin{tabular}{|c|c|c|c|c|}
\hline & $\begin{array}{l}\text { Non-AP patients } \\
(n=356)\end{array}$ & AP patients $(n=349)$ & OR $(95 \% \mathrm{Cl})$ & $p$ \\
\hline Smoking, n (\%) & $62(17.4)$ & $125(35.8)$ & $2.441(1.865-5.172)$ & $<0.001$ \\
\hline Alcohol drinking, n (\%) & $53(14.9)$ & $101(28.9)$ & $1.777(1.060-2.977)$ & 0.029 \\
\hline Biliary stone, n (\%) & $8(2.3)$ & $101(28.9)$ & $28.995(13.253-63.435)$ & $<0.001$ \\
\hline Hepatitis B, n (\%) & $17(4.8)$ & $7(2.0)$ & $0.439(0.145-1.327)$ & 0.145 \\
\hline Obesity, n (\%) & $120(33.7)$ & $157(45.0)$ & $1.258(0.854-1.855)$ & 0.246 \\
\hline $\mathrm{TC} \geq 220 \mathrm{mg} / \mathrm{dL}, \mathrm{n}(\%)$ & $61(17.1)$ & $106(30.4)$ & $1.992(1.246-3.183)$ & 0.004 \\
\hline $\mathrm{TG} \geq 150 \mathrm{mg} / \mathrm{dL}, \mathrm{n}(\%)$ & $97(27.2)$ & $162(46.4)$ & $2.134(1.403-3.245)$ & $<0.001$ \\
\hline $\begin{array}{l}\mathrm{HDL} \geq 40 \mathrm{mg} / \mathrm{dL}(\mathrm{M}) \text { or } \geq 50 \mathrm{mg} / \\
\mathrm{dL}(\mathrm{F}), \mathrm{n}(\%)\end{array}$ & $183(51.4)$ & $133(38.1)$ & $0.784(0.522-1.176)$ & 0.240 \\
\hline Apo $A \geq 1 \mathrm{~g} / \mathrm{L}, \mathrm{n}(\%)$ & $321(90.2)$ & $230(65.9)$ & $0.270(0.163-0.447)$ & $<0.001$ \\
\hline Hyperglycaemia, n (\%) & $37(10.4)$ & $93(26.7)$ & $2.261(1.367-3.742)$ & 0.001 \\
\hline Hypertension, n (\%) & $129(36.2)$ & $159(45.6)$ & $1.189(0.817-1.732)$ & 0.366 \\
\hline
\end{tabular}

$O R$ odds ratio, $T C$ total cholesterol, $T G$ triglyceride, $H D L$ high density lipoprotein, $A p o A$ apolipoprotein $A$

SI conversion factors: TC: $1 \mathrm{mg} / \mathrm{dL}=0.0259 \mathrm{mmol} / \mathrm{L} ; \mathrm{HDL}$, TG: $1 \mathrm{mg} / \mathrm{dL}=0.0113 \mathrm{mmol} / \mathrm{L}$ 
Table 4 Association between the metabolic syndrome and AP

\begin{tabular}{|c|c|c|c|}
\hline & $\begin{array}{l}\text { Prevalence } \\
\text { of metabolic } \\
\text { syndrome }\end{array}$ & OR $(95 \% \mathrm{Cl})$ & $p$ \\
\hline AP patients, n (\%) & $108(30.9)$ & $2.837(1.873-4.298)$ & $<0.001$ \\
\hline $\begin{array}{l}\text { Non-AP patients, } \\
\text { n (\%) }\end{array}$ & $47(13.2)$ & & \\
\hline
\end{tabular}

$p<0.001, p<0.001)$; their AUCs were 0.620, 0.679 and 0.767 , respectively. Among the three indicators, FPG had the best sensitivity $(67.54 \%)$, and TG had the best specificity $(90.17 \%)$ when the indicators were at their best cutoff values (shown in Table 5).

\section{Association between the number of metabolic syndrome components and AP}

As shown in Fig. 2, the incidence rates of AP obviously increased when there were more than three components of metabolic syndrome present. Moreover, the incidence rates of AP significantly declined when there were no components of metabolic syndrome present.

\section{Discussion}

To our knowledge, this is the first case-control study demonstrating the relationship between metabolic syndrome and the occurrence of AP in an Asian population. Our results showed that metabolic syndrome was positively associated with the occurrence of AP. Among components of metabolic syndromes, we revealed that hyperglycaemia and hyperlipidaemia were independently associated with AP.

Hyperglycaemia has been considered to be associated with AP for decades [20]. However, only a few studies have shown a higher incidence rate of AP among patients with hyperglycaemia [13-16]. Our results revealed that hyperglycaemia had positively correlation with AP (OR 2.261; 95\% CI 1.367-3.742, $p=0.001$ ). Although the exact mechanism between hyperglycaemia and AP remains unclear, several underlying biological theories have been proposed. High plasma glucose enhances mitochondrial

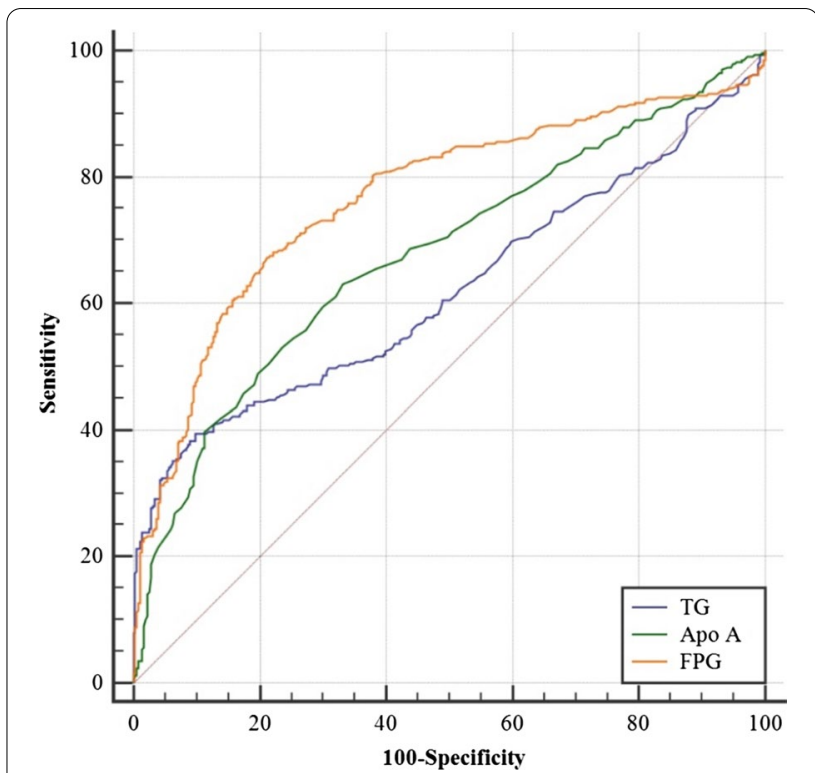

Fig. 1 Receiver operating characteristic (ROC) curve analysis for predicting the occurrence of AP by TG, Apo A and FPG in the estimation cohorts. AP acute pancreatitis, TG triglyceride, Apo A apolipoprotein A, FPG fasting plasma glucose

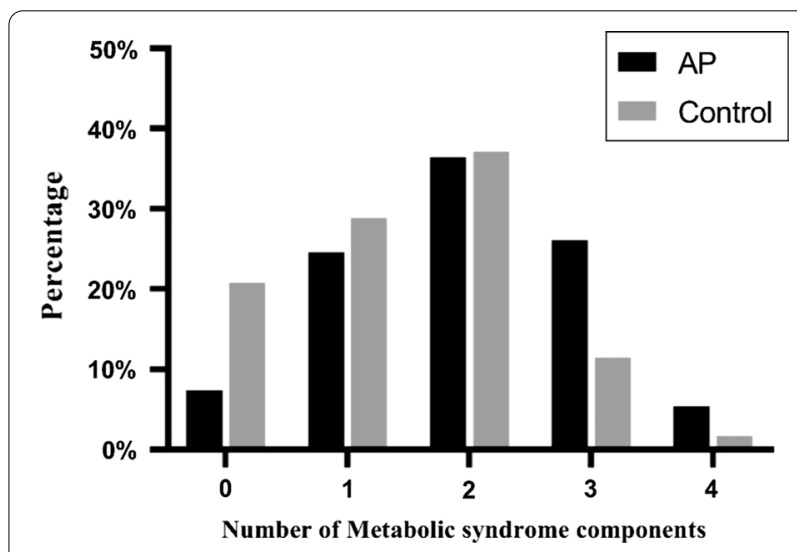

Fig. 2 The number of metabolic syndrome components in relation to the occurrence of AP. AP acute pancreatitis

oxidative stress by promoting the production of reactive oxygen species (ROS) and lipid oxidation through cytosolic $\mathrm{Ca}^{2+}$ accumulation [21-23]. Furthermore, owing to

Table 5 Identification of TG, Apo A and FPG in the patients with AP

\begin{tabular}{|c|c|c|c|c|c|c|c|}
\hline Variable & AUC & $p$ & Cut-off & Sensitivity (\%) & Specificity (\%) & $+\mathrm{LR}$ & $-\mathrm{LR}$ \\
\hline $\mathrm{TG}, \mathrm{mg} / \mathrm{dL}$ & 0.620 & $<0.001$ & 218.6 & 39.08 & 90.17 & 3.98 & 0.68 \\
\hline Apo A, g/L & 0.679 & $<0.001$ & 1.15 & 63.16 & 66.85 & 1.91 & 0.55 \\
\hline $\mathrm{FPG}, \mathrm{mg} / \mathrm{dL}$ & 0.767 & $<0.001$ & 115.1 & 67.54 & 78.93 & 3.21 & 0.41 \\
\hline
\end{tabular}

$A U C$ area under curve, $L R$ likelihood ratio, $T G$ triglyceride, $A p o A$ apolipoprotein $A, F P G$ fasting plasma glucose

SI conversion factors: TG: $1 \mathrm{mg} / \mathrm{dL}=0.0113 \mathrm{mmol} / \mathrm{L} ; \mathrm{FPG}: 1 \mathrm{mg} / \mathrm{dL}=0.0555 \mathrm{mmol} / \mathrm{L}$ 
the dysfunction of beta cells and resultant hyperinsulinaemia, beta cells may lose their sensitivity to the inhibitory hormone somatostatin, which may be an important factor in inducing AP [24]. Moreover, insulin resistance, as a crucial pathophysiological factor of hyperglycaemia, has been reported to be involved in AP development. Various proinflammatory factors or cytokines are activated due to insulin resistance, including nuclear factorkappaB (NF $\kappa B$ ), tumour necrosis factor-alpha (TNF- $\alpha$ ), amylin and interleukin- 6 , and these proinflammatory factors may be responsible for the initiation and progression of AP [25-29].

It is well known that hypertriglyceridaemia is associated with the morbidity and mortality of AP [30-32]. Our study showed that TG was associated with AP. Furthermore, we found that TC and Apo A values were also correlated with the occurrence of AP, which demonstrated that atherogenic lipid profiles also participated in the development of AP. Triantafilou M et al. reported that cholesterol may trigger inflammatory responses that could lead to chronic inflammation and insulin resistance via Toll-like receptor 4 (TLR4) and ultimately cause lysosomal damage, ROS generation and proinflammatory cytokine secretion $[33,34]$. This theory may explain why acinar injury is induced by hypercholesterolaemia through the inflammatory response. Furthermore, as a lipoprotein, HDL often opposes cholesterol accumulation and reduces inflammation by the ATP-binding cassette transporter A1 (ABCA1) pathway [35]. This ability may be impaired if Apo A is oxidized by macrophage myeloperoxidase (MPO). Shao B et al. reported impaired function of HDL and Apo A in patients with atherosclerosis [36], which may be similar in AP. However, our results only showed that the value of Apo A was negatively associated with the occurrence of AP, while we did not observe an association between HDL and AP. Based on our present study, it is hard to tease out the exact role of HDL in AP. In future studies, it will be important to determine the exact function that HDL and Apo A exert in AP development.

Currently, obesity is considered a global pandemic that poses a great threat to human health. Some studies have shown that obesity is positively correlated with the severity of AP [12, 37, 38]. However, due to the paucity of studies between obesity and the incidence of AP, their relationship has been a matter of dispute. Blomgren et al. found that the crude risk ratio (RR) between obesity and the occurrence of AP was 1.8 (95\% CI 1.3-2.6), while the authors did not display the results after adjustment [39]. In contrast to previous beliefs, our current study did not find an association between obesity and $\operatorname{AP}(p=0.246)$, which is consistent with the findings of a recent largescale prospective cohort study $(\mathrm{RR}=1.02,95 \% \mathrm{CI}$
0.68-1.53) [40]. In an animal model, obesity was shown to be related to an inflammatory status by secreting proinflammatory cytokines such as TNF- $\alpha$ and interleukin- 6 [41]. Moreover, the level of adiponectin, an anti-inflammatory cytokine, is reduced in an obese environment. Therefore, combined with previous data and our results [12], we suppose that obesity may aggravate the severity of AP but is not enough to initiate the development of AP without other risk factors in a non-AP person.

Recently, visceral obesity, a subtype of obesity, is considered as a metabolically active status. Previous study suggested that occurrence of biliary pancreatitis was positively correlated with intrapancreatic fat. It may be caused by saturation of cholesterol in bile, which could consequently induce gallstone formation [42]. Moreover, visceral fat was also associated with the severity of AP [43]. The level of adiponectin would paradoxically decrease due to excess viscera fat, which would subsequently increase the secretion of proinflammatory cytokines such as TNF- $\alpha$ and interleukin-6, and thus amplify the inflammatory response [44, 45]. Meanwhile, severe lipo-toxicity caused by visceral obesity could also induce the organ failure in AP patients [46]. However, our data did not show the significant difference between obesity and AP since only general obesity was measured in the current study. The different clinical outcomes that induced by general obesity and visceral obesity may be a kind of obesity paradox, even though its mechanism is still unclear. Therefore, future studies need to focus on this obesity paradox.

The limitations of our study are as follows: (1) Our study is a retrospective hospital-based case-control study, which can only assess the association. Prospective studies are needed to evaluate the causation between metabolic syndrome and AP in the future. (2) The visceral adiposity was not assessed and obesity was only measured by BMI in the current study. (3) Although we found a strong association between metabolic syndrome components and AP, we did not evaluate the effect of the treatment of each component on individuals, which may have an impact on the results. The major strengths are as follows: (1) This is the first study to illustrate the association between metabolic syndrome and the development of AP in an Asian population. (2) Given the completeness of behavioural and epidemiologic data, we can ensure the accuracy of clinical diagnosis and high quality of data and minimize recall bias.

\section{Conclusions}

The study revealed that patients with metabolic syndrome were associated with high incidence rates of AP. Regarding metabolic syndrome components, high levels of TC, TG, and FPG and low values of Apo A were 
independently associated with the development of AP. Since metabolic syndrome can be treated by lifestyle alterations or pharmacological treatment, we are looking forward to exploring this potential method to impede the increasing incidence rates of AP.

\section{Abbreviations}

AP: Acute pancreatitis; CT: Computed tomography; ECG: Electrocardiogram; BMI: Body mass index; TC: Total cholesterol; TG: Triglyceride; HDL: High density lipoprotein; LDL: Low density lipoprotein; Apo A: Apolipoprotein A; Apo B: Apolipoprotein B; FPG: Fasting plasma glucose; T2DM: Type 2 diabetes mellitus; OR: Odds ratio; Cl: Confidence interval; AUC: Area under curve; LR: Likelihood ratio; ROS: Reactive oxygen species; NF-KB: Nuclear factor-kappaB; TNF-a: Tumour necrosis factor-alpha; TLR4: Toll-like receptor 4; ABCA1: ATP-binding cassette transporter A1; MPO: Macrophage myeloperoxidase; RR: Risk ratio; ROC: Receiver operating characteristic.

\section{Acknowledgements}

Not applicable.

\section{Authors' contributions}

PLS proposed and designed the study. ZMS and XQW contributed equally to the article in the aspects of writing the manuscript and statistical analysis; ZLZ and YW also made essential contribution to data acquisition, analysis and interpretation. All authors were involved in critical revision of the manuscript. All authors read and approved the final manuscript.

\section{Funding}

The study received no funding.

\section{Availability of data and materials}

The datasets generated during the current study are not publicly available due to confidentiality of human subjects but are available from the corresponding author on reasonable request.

\section{Ethics approval and consent to participate}

The study was conducted according to the Declaration of Helsinki and approved by the institutional research board of Jinshan Hospital (IEC2020-S21). Informed consent was waived due to the retrospective nature of this study and the fact that patients were deidentified.

\section{Consent for publication}

Not applicable.

\section{Competing interests}

The authors declare that they have no competing interests.

\section{Author details}

1 Department of General Surgery, Jinshan Hospital, Fudan University, Shanghai, China. ${ }^{2}$ Department of Otorhinolaryngology Head and Neck Surgery, Jinshan Hospital, Fudan University, Shanghai, China. ${ }^{3}$ Department of Orthopedics, Jinshan Hospital, Fudan University, Shanghai, China.

Received: 16 July 2020 Accepted: 9 December 2020

Published online: 06 January 2021

\section{References}

1. Sawalhi S, Al-Maramhy H, Abdelrahman Al, Allah SE, Al-Jubori S. Does the presence of obesity and/or metabolic syndrome affect the course of acute pancreatitis? A prospective study. Pancreas. 2014;43(4):565-70.

2. Lowenfels AB, Maisonneuve P, Sullivan T. The changing character of acute pancreatitis: epidemiology, etiology, and prognosis. Curr Gastroenterol Rep. 2009;11(2):97-103.

3. Lankisch PG, Apte M, Banks PA. Acute pancreatitis. Lancet. 2015;386:85-96.
4. Song QB, Zhao Y, Liu YQ, Zhang J, Xin SJ, Dong GH. Sex difference in the prevalence of metabolic syndrome and cardiovascular-related risk factors in urban adults from 33 communities of China: the CHPSNE study. Diabetes Vasc Dis Res. 2015;12(3):189-98.

5. Eckel RH, Grundy SM, Zimmet PZ. The metabolic syndrome. Lancet. 2005;365(9468):1415-28.

6. Kassi E, Pervanidou P, Kaltsas G, Chrousos G. Metabolic syndrome: definitions and controversies. BMC Med. 2011;9:48.

7. Huang PL. A comprehensive definition for metabolic syndrome. Dis Model Mech. 2009;2(5-6):231-7.

8. Jang MJ, Choi WI, Bang SM, Lee T, Kim YK, Ageno W, et al. Metabolic syndrome is associated with venous thromboembolism in the Korean population. Arterioscler Thromb Vasc Biol. 2009;29(3):311-5.

9. Gisondi P, Fostini AC, Fossà I, Girolomoni G, Targher G. Psoriasis and the metabolic syndrome. Clin Dermatol. 2018;36(1):21-8.

10. Grandl G, Wolfrum C. Hemostasis, endothelial stress, inflammation, and the metabolic syndrome. Semin Immunopathol. 2018;40(2):215-24.

11. Habtezion A. Inflammation in acute and chronic pancreatitis. Curr Opin Gastroenterol. 2015;31(5):395-9.

12. Mikolasevic I, Milic S, Orlic L, Poropat G, Jakopcic I, Franjic N, et al. Metabolic syndrome and acute pancreatitis. Eur J Intern Med. 2016;32:79-83.

13. Girman CJ, Kou TD, Cai B, Alexander CM, O'Neill EA, Williams-Herman DE, et al. Patients with type 2 diabetes mellitus have higher risk for acute pancreatitis compared with those without diabetes. Diabetes Obes Metab. 2010;12(9):766-71.

14. Lai SW, Muo CH, Liao KF, Sung FC, Chen PC. Risk of acute pancreatitis in type 2 diabetes and risk reduction on anti-diabetic drugs: a populationbased cohort study in Taiwan. Am J Gastroenterol. 2011;106(9):1697-704.

15. Garg R, Chen W, Pendergrass M. Acute pancreatitis in type 2 diabetes treated with exenatide or sitagliptin: a retrospective observational pharmacy claims analysis. Diabetes Care. 2010;33(11):2349-54.

16. Noel RA, Braun DK, Patterson RE, Bloomgren GL. Increased risk of acute pancreatitis and biliary disease observed in patients with type 2 diabetes: a retrospective cohort study. Diabetes Care. 2009;32(5):834-8.

17. Banks PA, Bollen TL, Dervenis C, Gooszen HG, Johnson CD, Sarr MG, et al. Classification of acute pancreatitis-2012: revision of the Atlanta classification and definitions by international consensus. Gut. 2013;62(1):102-11.

18. Executive Summary of the third report of The National Cholesterol Education Program (NCEP). Expert panel on detection, evaluation, and treatment of high blood cholesterol in adults (Adult Treatment Panel III). JAMA. 2001;285(19):2486-97.

19. Garvey WT, Mechanick Jl, Brett EM, Garber AJ, Hurley DL, Jastreboff AM, et al. American Association of Clinical Endocrinologists and American College of Endocrinology comprehensive clinical practice guidelines for medical care of patients with obesity. Endocr Pract. 2016;22(Suppl 3):1-203.

20. Shumacker HB. Acute pancreatitis and diabetes. Ann Surg. 1940;112(2):177-200.

21. Kamboj SS, Sandhir R. Protective effect of N-acetylcysteine supplementation on mitochondrial oxidative stress and mitochondrial enzymes in cerebral cortex of streptozotocin-treated diabetic rats. Mitochondrion. 2011;11(1):214-22.

22. Yu T, Jhun BS, Yoon Y. High-glucose stimulation increases reactive oxygen species production through the calcium and mitogen-activated protein kinase-mediated activation of mitochondrial fission. Antioxid Redox Signal. 2011;14(3):425-37.

23. Sugimoto R, Enjoji M, Kohjima M, Tsuruta S, Fukushima M, Iwao M, et al. High glucose stimulates hepatic stellate cells to proliferate and to produce collagen through free radical production and activation of mitogen-activated protein kinase. Liver Int. 2005;25(5):1018-26.

24. Stumvoll M, Goldstein BJ, van Haeften TW. Type 2 diabetes: principles of pathogenesis and therapy. Lancet. 2005;365(9467):1333-46.

25. Rakonczay Z Jr, Hegyi P, Takacs T, McCarroll J, Saluja AK. The role of NF-kappaB activation in the pathogenesis of acute pancreatitis. Gut. 2008;57(2):259-67.

26. Grewal HP, Kotb M, el Din AM, Ohman M, Salem A, Gaber L, et al. Induction of tumor necrosis factor in severe acute pancreatitis and its subsequent reduction after hepatic passage. Surgery. 1994;115(2):213-21.

27. Nieto-Vazquez I, Fernandez-Veledo S, Kramer DK, Vila-Bedmar R, GarciaGuerra L, Lorenzo M. Insulin resistance associated to obesity: the link TNF-alpha. Arch Physiol Biochem. 2008;1 14(3):183-94. 
28. Phillips AR, Abu-Zidan FM, Bonham MJ, Cooper GJ, Windsor JA. Amylin and severe acute pancreatitis. Pancreas. 2000;20(1):105-6.

29. Jambrik Z, Gyongyosi M, Hegyi P, Czako L, Takacs T, Farkas A, et al. Plasma levels of IL-6 correlate with hemodynamic abnormalities in acute pancreatitis in rabbits. Intensive Care Med. 2002;28(12):1810-8.

30. Fortson MR, Freedman SN, Webster PD 3rd. Clinical assessment of hyperlipidemic pancreatitis. Am J Gastroenterol. 1995;90(12):2134-9.

31. Tsuang W, Navaneethan U, Ruiz L, Palascak JB, Gelrud A. Hypertriglyceridemic pancreatitis: presentation and management. Am J Gastroenterol. 2009;104(4):984-91.

32. Valdivielso P, Ramirez-Bueno A, Ewald N. Current knowledge of hypertriglyceridemic pancreatitis. Eur J Intern Med. 2014;25(8):689-94.

33. Triantafilou M, Miyake K, Golenbock DT, Triantafilou K. Mediators of innate immune recognition of bacteria concentrate in lipid rafts and facilitate lipopolysaccharide-induced cell activation. J Cell Sci. 2002;115(Pt 12):2603-11.

34. Li HB, Jin C, Chen Y, Flavell RA. Inflammasome activation and metabolic disease progression. Cytokine Growth Factor Rev. 2014;25(6):699-706.

35. Moore KJ, Tabas I. Macrophages in the pathogenesis of atherosclerosis. Cell. 2011;145(3):341-55.

36. Shao B, Tang C, Sinha A, Mayer PS, Davenport GD, Brot N, et al. Humans with atherosclerosis have impaired $A B C A 1$ cholesterol efflux and enhanced high-density lipoprotein oxidation by myeloperoxidase. Circ Res. 2014;114(11):1733-42.

37. Funnell IC, Bornman PC, Weakley SP, Terblanche J, Marks IN. Obesity: an important prognostic factor in acute pancreatitis. Br J Surg. 1993;80(4):484-6.

38. Martínez J, Sánchez-Payá J, Palazón JM, Aparicio JR, Picó A, Pérez-Mateo M. Obesity: a prognostic factor of severity in acute pancreatitis. Pancreas. 1999;19(1):15-20.
39. Blomgren KB, Sundström A, Steineck G, Wiholm BE. Obesity and treatment of diabetes with glyburide may both be risk factors for acute pancreatitis. Diabetes Care. 2002;25(2):298-302.

40. Sadr-Azodi O, Orsini N, Andren-Sandberg A, Wolk A. Abdominal and total adiposity and the risk of acute pancreatitis: a population-based prospective cohort study. Am J Gastroenterol. 2013;108(1):133-9.

41. Lee $\mathrm{YH}$, Pratley RE. The evolving role of inflammation in obesity and the metabolic syndrome. Curr Diabetes Rep. 2005;5(1):70-5.

42. Singh RG, Cervantes A, Kim JU, Nguyen NN, DeSouza SV, Dokpuang D, et al. Intrapancreatic fat deposition and visceral fat volume are associated with the presence of diabetes after acute pancreatitis. Am J Physiol Gastrointest Liver Physiol. 2019;316(6):806-15.

43. Natu A, Stevens T, Kang L, Yasinow S, Mansoor E, Lopez R, et al. Visceral adiposity predicts severity of acute pancreatitis. Pancreas. 2017;46(6):776-81.

44. Lara-Castro C, Fu Y, Chung BH, Garvey WT. Adiponectin and the metabolic syndrome: mechanisms mediating risk for metabolic and cardiovascular disease. Curr Opin Lipidol. 2007;18(3):263-70.

45. Karpavicius A, Dambrauskas Z, Sileikis A, Vitkus D, Strupas K. Value of adipokines in predicting the severity of acute pancreatitis: comprehensive review. World J Gastroenterol. 2012;18(45):6620-7.

46. Patel K, Trivedi RN, Durgampudi C, Noel P, Cline RA, DeLany JP, et al. Lipolysis of visceral adipocyte triglyceride by pancreatic lipases converts mild acute pancreatitis to severe pancreatitis independent of necrosis and inflammation. Am J Pathol. 2015;185(3):808-19.

\section{Publisher's Note}

Springer Nature remains neutral with regard to jurisdictional claims in published maps and institutional affiliations.
Ready to submit your research? Choose BMC and benefit from:

- fast, convenient online submission

- thorough peer review by experienced researchers in your field

- rapid publication on acceptance

- support for research data, including large and complex data types

- gold Open Access which fosters wider collaboration and increased citations

- maximum visibility for your research: over $100 \mathrm{M}$ website views per year

At BMC, research is always in progress.

Learn more biomedcentral.com/submissions 